\title{
The Health and Working Conditions of Women Employed in Child Care
}

\author{
Laura Linnan ${ }^{1,2, *}$, Gabriela Arandia ${ }^{1}$, Lori A. Bateman ${ }^{2}$, Amber Vaughn ${ }^{2}$, Natalie Smith ${ }^{3}$ \\ and Dianne Ward ${ }^{2,4}$ \\ 1 Department of Health Behavior, Gillings School of Global Public Health, University of North Carolina at \\ Chapel Hill, Chapel Hill, NC 27599, USA; arandia@live.unc.edu \\ 2 Center for Health Promotion and Disease Prevention, University of North Carolina at Chapel Hill, \\ Chapel Hill, NC 27599, USA; lbateman@email.unc.edu (L.A.B.); avaughn@email.unc.edu (A.V.); \\ dsward@email.unc.edu (D.W.) \\ 3 Department of Biostatistics, Gillings School of Global Public Health, University of North Carolina at \\ Chapel Hill, Chapel Hill, NC 27599, USA; natsmith@live.unc.edu \\ 4 Department of Nutrition, Gillings School of Global Public Health, University of North Carolina at \\ Chapel Hill, Chapel Hill, NC 27599, USA \\ * Correspondence: linnan@email.unc.edu; Tel.: +1-919-843-8044
}

Academic Editor: Paul B. Tchounwou

Received: 13 January 2017; Accepted: 5 March 2017; Published: 9 March 2017

\begin{abstract}
Over one million women are employed in child care and are among the lowest wage workers in the US. The health and working conditions of 674 child care workers (118 administrators and 556 staff) from 74 centers is described using baseline data from a larger intervention trial. Participants were 39.9 ( \pm 13.0 ) years old; 55.4\% African American, 37.1\% Caucasian, and 5.3\% of Hispanic ethnicity. Seventy-six percent reported having an Associate's degree or less; $42 \%$ were classified as at or below poverty $(<\$ 20,000)$; and exhibited many health risks such as excess weight, insufficient activity, poor diet, and inadequate sleep. We investigated potential differences by income and job category. Lower income participants were significantly more likely to be current smokers (19.9\% vs. $11.7 \%$ ), drink more sweetened beverages (1.9 vs. 1.5), and report higher depressive symptoms (15.5 vs. 12.6). Administrators worked more hours weekly compared to staff (46.4 vs. 40.6), are less active (100 vs. $126 \mathrm{~min} /$ week), more sedentary (501 vs. $477 \mathrm{~min} /$ day), and reported higher job demands (13.3 vs. 12.5). Given the numerous health issues and challenging work conditions, we hope our results serve as a call to action for addressing low wages and the work environment as a means of influencing the health and well-being of child care workers.
\end{abstract}

Keywords: low wage workers; child care workers; work conditions; job strain

\section{Introduction}

There are more than 1.3 million child care workers in the U.S. [1] of which 95.5\% are women [2]. In fact, child care is one of the 10 most prevalent occupations for women [2]. While they are entrusted with our most valuable asset, our children, child care workers are among the lowest paid occupations, often having earnings below poverty level [3,4]. The 2016 Occupation Outlook Handbook reports that the average pay for child care workers in the U.S. is $\$ 9.77$ per hour or $\$ 20,320$ annually [1]. As low wage workers, they likely face higher rates of chronic disease and shorter life expectancies [5-7]. Furthermore, low wage workers often experience challenging working conditions as demonstrated in a review by Landsbergis and colleagues who found that low wage workers were more likely to experience higher job insecurity and job strain than higher wage workers [8].

Very little information is available about the health status of child care workers. The largest study with more than 2000 female child care workers in Pennsylvania found that $75 \%$ had one or more chronic 
health conditions and $20 \%$ had three or more conditions [9]. However, the sample was limited to employees at Head Start, a federally-sponsored program that provides comprehensive early childhood education, health, nutrition, and parent engagement services to low-income children and their families. While Head Start programs have more standardized organizational structure and financial support compared to center-based programs, the study suggests that many of the workers were still struggling with multiple health issues. Among the few other studies with child care workers, results suggest elevated levels of emotional distress [10], multiple health risk behaviors [11], and increased prevalence of overweight and obesity [12].

Working conditions such as long hours, high job demands, low wages, lack of health benefits, and high turn-over may be impacting the health of child care workers. A recent review by Cumming on child care workers' well-being identified 30 studies conducted in the U.S. and abroad that help document these challenging working conditions, several of which also demonstrated how these work conditions are related to adverse effects on workers' psychological and emotional health [13]. Other studies have shown that the working conditions of the child care job can place workers at risk for infectious diseases, injuries, and other occupational hazards [14-16]. Unfortunately, very few studies have examined the relationship between working conditions and workers' physical and emotional health status and/or health behaviors.

The purpose of this study is to describe the health status, health behaviors, and working conditions of child care workers and to explore how income and job position may be associated. We believe considering working conditions will address an important gap in the literature about the health of child care workers. We will also discuss the implications of these results for both practice and research that might improve the health and working conditions for child care workers in the future.

\section{Materials and Methods}

This study used baseline data from a group randomized control trial (ClinicalTrials.gov registration number NCT02381938) conducted in North Carolina to evaluate the impact of a child care-based worksite wellness intervention. For the purpose of this paper, we used baseline data only, collected prior to randomization and intervention implementation. All protocols were approved by the Institutional Review Board at the University of North Carolina at Chapel Hill (\#13-2438).

\subsection{Sample Recruitment and Eligibility}

A convenience sample of child care centers and their workers, both administrators and staff, were recruited to join a group randomized control research trial using a multi-phase recruitment strategy. We targeted counties in North Carolina where we had existing community partners that could help facilitate an introduction to local child care centers. Moreover, we targeted geographical areas that had sufficient numbers of medium to large centers to ensure that we would reach recruitment goals. Across four waves, we recruited seven counties that represented a combination of rural, suburban, and urban area, moderate to low income, and similar racial and ethnic populations compared to the state. Centers in these counties were identified from an online database of licensed child care programs available through the North Carolina Division of Child Development and Early Education [17]. Following introductions from the community partners, the research team initiated direct contact with local child care centers via mail/email letters of invitation and follow up telephone calls. During calls, research assistants confirmed center eligibility, reviewed study details, and assessed center interest. Eligible centers had to be in business for at least two years with no plans to close in the following 18 months and have at least four employees (one administrator and three additional staff) willing to participate. Once center eligibility was confirmed, research assistants met with interested staff in-person to confirm eligibility, review study details, and collect informed consent. Eligible staff had to be at least 18 years old, able to read and speak English, and pass a physical activity readiness screening (PAR-Q+ [18]) (and obtain medical approval if required). 


\subsection{Data Collection and Measures}

Participants completed several measures, including physical assessments, physical activity monitoring, and web-based and paper surveys. Data were collected primarily during an onsite visit by data collectors who were trained and certified on all protocols. Specific measures are described below:

Physical Assessments. Height, weight, waist circumference, heart rate, and blood pressure were assessed using standard protocols $[19,20]$. Height was measured to the nearest $1 / 8$ inch with a Shorr measuring board (Shorr Productions, Olney, MD, USA). Weight was measured to the nearest 0.1 pound with a Seca model 874 portable electronic scale (Seca Corporation, Columbia, MD, USA). Height and weight measures were taken with shoes and heavy clothing removed. Waist circumference was measured with a Gulick II (Patterson Medical, Warrenville, IL, USA) measuring tape to the nearest $0.1 \mathrm{~cm}$ at the level of the iliac crest. Heart rate and blood pressure were assessed using a digital blood pressure monitor (Omron, Kyoto, Japan) while participants sat quietly with their legs uncrossed and feet flat on the floor. All measures were taken twice. If the two measurements were within reasonable agreement ( $\leq 1 / 4$ inch for height, $\leq 1.0 \mathrm{lb}$. for weight, $\leq 3.0 \mathrm{~cm}$ for waist circumference, and $<5 \mathrm{mmHg}$ for systolic and diastolic blood pressure) the final measure was recorded as the average of the two values. Otherwise, a third measure was taken. Height and weight were used to calculate body mass index (BMI) (weight in $\mathrm{kg} /$ height in $\mathrm{m}^{2}$ ) and weight status (underweight $=\mathrm{BMI}<18.5$, normal weight $=$ BMI 18.5-24.9, overweight $=$ BMI 25.0-29.9, obese $=$ BMI $\geq 30.0$ ). Systolic and diastolic blood pressure were used to determine mean arterial pressure.

Physical Activity Monitoring. Physical activity was assessed using one week of accelerometer monitoring using a GT3X ActiGraph monitor (ActiGraph LLC, Pensacola, FL, USA). Participants were fit with a belt that allowed the monitor to be worn over the right hip and were instructed to wear the monitor for the next seven days, $24 \mathrm{~h}$ a day except during water activities. Monitors were programmed to sample at $30 \mathrm{~Hz}$. Data from the monitor were downloaded using ActiLife software (ActiGraph LLC). Adult-specific cut points were applied to determine minutes of sedentary activity ( $0-100$ counts $/ \mathrm{min}$, $<1.5$ METS) and minutes of moderate-to-vigorous physical activity (MVPA) ( $\geq 2020$ counts $/ \mathrm{min}$, 3.0 METS) [21,22] for participants with at least eight hours of wear time on a minimum of four days.

Web-Based Surveys. Health behaviors were assessed using a series of self-administered surveys collected via an online system known as the Carolina Health Assessment and Research Tool (CHART) [23]. More specifically, CHART assessed dietary intake, tobacco and e-cigarette use, sleep, and emotional health.

Dietary intake was assessed using items from the Dietary Screener Questionnaire $[24,25]$ and the Diet History Questionnaire [26]. Within this survey, five items asked specifically about intake of fruits, fruit juice, potatoes, beans and legumes, and other vegetables; and two items asked about intake of sugar-sweetened and artificially-sweetened beverages. The five items related to fruits and vegetables were summed to get a total daily fruit and vegetable intake; and the two items related to beverages were summed to get a total sweetened beverage intake.

Tobacco and e-cigarette use was assessed using two items modified from the 2012 Behavioral Risk Factor Surveillance System Questionnaire (BRFSS) [27] that asks participants to estimate the average use of each during the past 30 days. Items were used to identify participants that are current smokers or had ever used e-cigarettes.

Sleep duration was assessed using one item extracted from the Pittsburgh Sleep Quality Index (PSQI) [28], which asked participants to estimate their typical hours of sleep per night during the past 30 days.

Emotional health was assessed using a combination of indices related to distress, depressive symptoms and job strain. Distress was measured using one item from the Society for Behavioral Medicine's Common Data Elements [29] which asked participants to rate their level of distress during the past week on a scale of 0 to $10(0=$ no distress, $10=$ extreme distress $)$. Depressive symptoms were measured using the 20-item Center for Epidemiologic Studies Depression Scale (CES-D) [30]. As specified in standard scoring protocols, item responses (scored 0-3) are reverse-coded when 
appropriate and summed to create a total depressive symptom score (ranging from $0-60$ ) with $\geq 16$ indicating high risk of clinical depression. Job strain indicators were measured with 15 items derived from the Job Content Questionnaire (JCQ) [31], specifically items required to calculate job demand (scores ranging from 5-20), job control (scores ranging from 12-48), and job insecurity $(0,1)$. These items ranged from 1 (strongly disagree) to 4 (strongly agree) and were reverse-coded when necessary. Job demands was composed of 5 items (e.g., "My job requires working very fast") and a higher score indicates more job demands. Job control is comprised of two subscales, skill discretion (6 items, e.g., "My job requires me to learn new things") and decision authority ( 3 items, e.g., "I have a lot to say about what happens at my job") and a higher score indicates less job control. Job insecure participants answered "Strongly disagree" or "Disagree" to "My job security is good" [32].

The web-based surveys also captured demographic variables including age, sex, race, ethnicity, education, marriage status, household size, household income, and hours worked (at the enrolled childcare center plus any from a second job). Household income (assessed categorically) was used to identify participants as below poverty $(<\$ 20,000)$ or above poverty $(\geq \$ 20,000)$. The below poverty cut point was based on the median household size in our sample (three) and income thresholds set in the 2016 Federal Poverty Guidelines [33] (\$20,160 for a household of three). Seventy-four participants declined to answer this question, and were thus considered missing for income-related analyses.

Among these demographic items, there was also a question that asked participants to identify their role at the center (e.g., job position), with response options including owner, director, assistant director, lead teacher, assistant teacher, and other. Administrators (defined as owner, director, or assistant director) were asked additional questions about center demographics, including years of operation, hours of operation, enrollment fees, star rating, number of kids in care, number of employees, center type, current participation in the Child Adult Care Food Program (CACFP), and accreditation by the National Association for the Education of Young Children (NAEYC). CACFP is a federally-funded U.S. program that provides reimbursement for meals and snacks served in child care programs that serve low-income families. The NC's Quality Rating and Improvement Systems (QRIS) [34] star rating is an indicator of quality based on a five-point scale, where a rating of one star corresponds to meeting minimum licensing standards and five stars represents the highest quality and voluntarily compliance with higher standards related to programming and staff education.

\subsection{Statistical Analysis}

First, we examined descriptive summary statistics (Tables 1 and 2). Drawing from the measures described above, we examined demographic characteristics (e.g., age, sex, race and ethnicity, education), indicators of health status and behavior (e.g., weight, waist circumference, heart rate, blood pressure, diet, physical activity, cigarette and e-cigarette use, sleep, emotional health), and indicators of working conditions (e.g., hours worked, job demand, job control, job security). Next, we explored differences in health status, health behaviors, and working conditions by income status (below vs. above $\$ 20,000$ ) and job position (administrator vs. staff). Differences were assessed using chi-square tests (categorical outcomes) or two independent sample $t$-tests (continuous outcomes) using SAS software 9.4 (SAS Institute Inc., Cary, NC, USA). Due to the high number of hypothesis tests conducted, the raw $p$-values were adjusted to control for the overall Type I error rate; however, these adjusted $p$-values did not change any conclusions about statistical significance and thus the raw $p$-values are presented for simplicity in Tables 3 and 4 . 
Table 1. Participant demographics.

\begin{tabular}{lcc}
\hline Demographic & $N(\%)$ & Mean (SD) \\
\hline Age (years) & & $39.9(13.0)$ \\
\hline Sex & & \\
\hline Female & $674(100.0)$ \\
\hline Race & \\
\hline Caucasian & $244(37.1)$ \\
African American & $364(55.4)$ \\
Asian & $7(1.1)$ \\
American Indian/Alaskan Native & $13(2.0)$ \\
Other & $4(0.6)$ \\
Mixed & $25(3.8)$ \\
\hline Ethnicity & \\
\hline Hispanic & $36(5.3)$ \\
\hline Highest level of education & \\
\hline High school diploma/GED & $82(12.2)$ \\
Some college & $267(39.6)$ \\
Associate's degree & $163(24.2)$ \\
Bachelor's degree & $136(20.2)$ \\
Graduate, MS, or higher & $26(3.9)$ \\
\hline Married/living with a partner & $338(50.2)$ \\
\hline \# in household & \\
\hline Household income (annual) & \\
\hline$<$ 10 K & \\
\$10-15 K & $62(9.2)$ \\
\$20-25 K & $106(15.7)$ \\
\$25-35 K & $78(17.6)$ \\
\$50-75 K & $85(12.6)$ \\
p75 K & $47(11.4)$ \\
prefer not to answer & $36(5.3)$ \\
\hline Health insured & $74(11.0)$ \\
\hline & $506(75.1)$ \\
\hline
\end{tabular}

Table 2. Childcare center descriptors.

\begin{tabular}{lcc}
\hline Descriptor & $\boldsymbol{N ~ ( \% )}$ & Mean (SD) \\
\hline Years in operation & & $17.4(11.3)$ \\
Hours of operation & & $13.1(3.36)$ \\
Enrollment fee (dollars/week) * & $140.3(19.5)$ \\
Star rating & & $4.30(0.67)$ \\
Size & & \\
$\quad$ \# of children & & $56.3(32.5)$ \\
$\quad$ \# of employees & & $12.1(8.59)$ \\
Employee role & $118(17.5)$ & \\
$\quad$ Administrator & $556(82.5)$ & \\
$\quad$ Staff & $20(27.0)$ & \\
Faith-based & $1(1.4)$ & \\
Early Head Start & $49(68.1)$ & \\
Privately owned & $72(97.3)$ & \\
Accepts subsidies & $61(84.7)$ & \\
CACFP participation & $11(15.3)$ & \\
NAEYC accredited & & \\
\hline
\end{tabular}

* Average enrollment fee for a 3-5 year old. 
Table 3. Physical and mental health risk indicators.

\begin{tabular}{|c|c|c|c|c|c|c|c|}
\hline \multirow{2}{*}{ Variable } & \multicolumn{2}{|c|}{ All } & \multicolumn{2}{|c|}{ Below \$20 K } & \multicolumn{2}{|c|}{ Above $\$ 20 \mathrm{~K}$} & \multirow{2}{*}{$p$-Value } \\
\hline & $N(\%)$ & Mean (SD) & $N(\%)$ & Mean (SD) & $N(\%)$ & Mean (SD) & \\
\hline $\operatorname{BMI}\left(\mathrm{kg} / \mathrm{m}^{2}\right)$ & & $34.5(9.01)$ & & $34.8(9.24)$ & & $34.3(8.80)$ & 0.5194 \\
\hline Underweight & $5(0.8)$ & & $2(0.7)$ & & $3(1.0)$ & & \\
\hline Normal Weight & $64(10.7)$ & & $29(10.3)$ & & $35(11.0)$ & & \\
\hline Overweight & $133(22.2)$ & & $58(20.5)$ & & $75(23.7)$ & & \\
\hline Obese & $398(66.3)$ & & $194(68.6)$ & & $204(64.4)$ & & \\
\hline Body weight (kg) & & $90.4(25.1)$ & & $91.1(25.7)$ & & $89.8(24.6)$ & \\
\hline Waist circumference $(\mathrm{cm})$ & & $106.5(18.2)$ & & $106.9(18.8)$ & & $106.2(17.7)$ & 0.6024 \\
\hline Heart rate (bpm) & & $77.6(11.9)$ & & $78.2(11.4)$ & & $77.1(12.4)$ & 0.2829 \\
\hline Mean arterial pressure & & $94.6(14.0)$ & & $94.2(15.1)$ & & $94.9(13.0)$ & 0.5725 \\
\hline Systolic blood pressure $(\mathrm{mm} / \mathrm{Hg})$ & & $122.9(19.5)$ & & $122.2(20.9)$ & & $123.5(18.3)$ & \\
\hline Diastolic blood pressure $(\mathrm{mm} / \mathrm{Hg})$ & & $80.4(12.6)$ & & $80.1(13.7)$ & & $80.6(11.8)$ & \\
\hline MVPA (min/week) & & $122(104)$ & & $126(95.0)$ & & $120(110)$ & 0.5220 \\
\hline Meeting physical activity recommendations & $142(27.8)$ & & $67(29.8)$ & & $75(26.3)$ & & 0.3864 \\
\hline Sedentary time (min/day) & & $481(72.4)$ & & $468(73.1)$ & & $491(70.5)$ & $0.0006^{*}$ \\
\hline Current cigarette smoker & $93(15.6)$ & & $56(19.9)$ & & $37(11.7)$ & & $0.0057^{*}$ \\
\hline Ever used e-cigarettes & $59(9.9)$ & & $30(10.7)$ & & $29(9.2)$ & & 0.5402 \\
\hline Fruit and vegetable consumption (times/day) & & $2.58(1.72)$ & & $2.52(1.83)$ & & $2.64(1.61)$ & 0.4156 \\
\hline Sweetened beverage consumption (times/day) & & $1.71(1.82)$ & & $1.93(2.06)$ & & $1.51(1.56)$ & $0.0057^{*}$ \\
\hline Sleep duration (hours/night) & & $6.37(1.35)$ & & $6.34(1.39)$ & & $6.40(1.31)$ & 0.6399 \\
\hline Perceived level of distress & & $4.02(2.78)$ & & $4.10(2.82)$ & & $3.94(2.75)$ & 0.4652 \\
\hline CES-D score & & $13.9(9.17)$ & & $15.5(9.95)$ & & $12.6(8.22)$ & $0.0002 *$ \\
\hline CES-D $\geq 16$ & $215(36.1)$ & & $116(41.6)$ & & $99(31.3)$ & & 0.0094 * \\
\hline
\end{tabular}


Table 4. Job-related health risk indicators.

\begin{tabular}{|c|c|c|c|c|c|c|c|}
\hline \multirow{2}{*}{ Variable } & \multicolumn{2}{|c|}{ All } & \multicolumn{2}{|c|}{ Administrator } & \multicolumn{2}{|c|}{ Staff } & \multirow{2}{*}{$p$-Value } \\
\hline & $N(\%)$ & Mean (SD) & $N(\%)$ & Mean (SD) & $N(\%)$ & Mean (SD) & \\
\hline Hours worked (hours/week) & & $41.6(11.8)$ & & $46.4(12.2)$ & & $40.6(11.4)$ & $<0.0001 *$ \\
\hline Perceived job insecurity & 76 (11.4) & & $7(6.03)$ & & $69(12.5)$ & & 0.0468 \\
\hline Job demands (range 5-20) & & $12.6(2.19)$ & & $13.3(2.41)$ & & $12.5(2.12)$ & 0.0007 * \\
\hline Job control (range 12-48) & & $24.3(5.18)$ & & $21.6(5.04)$ & & $24.9(5.03)$ & $<0.0001 *$ \\
\hline Skill discretion (range 6-24) & & $12.2(2.31)$ & & $11.3(1.99)$ & & $12.4(2.33)$ & $<0.0001$ * \\
\hline Decision authority (range 6-24) & & $12.1(3.45)$ & & $10.2(3.51)$ & & $12.5(3.32)$ & $<0.0001 *$ \\
\hline
\end{tabular}

\section{Results}

\subsection{Participant Demographics}

While the full sample included 697 child care workers from 74 centers, we narrowed the sample to include only the 674 female workers (118 administrators and 556 staff) for this study. Demographic characteristics of these participants are presented in Table 1. On average, participants were 39.9 ( \pm 13.0 ) years old. The majority (55.4\%) were African American, 37.1\% were Caucasian, and $5.3 \%$ were of Hispanic ethnicity. The majority $(76.0 \%)$ of participants attained an Associate's degree or less. Forty two percent of participants were classified as at or below poverty (based on our cut point of $<\$ 20,000)$.

We explored demographic differences by job position (administrators vs. staff). Administrators were slightly older than staff (43.8 years vs. 39.1 years); were more likely to be White (45.7\% vs. 35.3\%); attained more education (46.6\% having completed a bachelor's degree or higher vs. $19.3 \%$ of staff); and had higher household incomes $(89.1 \%$ reported an income greater than $\$ 20,000$ vs. $44.7 \%$ of staff). Administrators were more likely to be married or living with a partner (63.6\% vs. $47.3 \%)$. No differences were observed between administrators and staff regarding household size.

\subsection{Child Care Center Demographics}

Seventy-four child care centers were enrolled in this study, demographics for which are described in Table 2. Participating centers had a high quality rating, averaging $4.3( \pm 0.7)$ stars. Centers had, on average, $56.3( \pm 32.5)$ children enrolled and 12.1 ( \pm 8.6$)$ staff employed. Centers reported being open for $13.1( \pm 3.4) \mathrm{h}$ per day and were predominately privately owned $(68.1 \%)$, though nearly all accepted subsidies (97.3\%) and participated in CACFP (84.7\%).

\subsection{Health Indicators Overall}

Participant health indicators are presented in Table 3. Participants appeared to have many indicators of poor health status and behavior. Participants' average BMI was $34.5( \pm 9.0)$ with $22.2 \%$ of participants classified as overweight and $66.3 \%$ classified as obese. Average waist circumference was $106.5 \mathrm{~cm}( \pm 18.2)$, well above the $88.0 \mathrm{~cm}$ cut point for women that is associated with increased risk for disease [35]. Twenty-six percent of participants had high blood pressure (defined as pressures at or above 140/90). Although we are unable to report on the use of blood pressure medication, 33.5\% of our sample reported on the PARQ+ (from the eligibility screening) being told by a physician that they have high blood pressure.

Regarding health behaviors, participants accumulated an average of $122( \pm 104)$ min per week of MVPA, which is below the recommended $150 \mathrm{~min}$ per week [36]. Also, participants accumulated $481( \pm 72.4)$ min per day of sedentary time, roughly $8 \mathrm{~h}$ a day. Participants reported eating fruits and vegetables an average of $2.58( \pm 1.72)$ times per day and drank sweetened beverages on average 1.71 $( \pm 1.82)$ times per day. Even if participants consumed a cup each time they ate fruits or vegetables, they still consumed far below the 3.5-4.5 cups per day that is recommended for women [37]. Overall, $15.6 \%$ were current smokers, and $9.9 \%$ reported having used an e-cigarette. On average, participants 
reported sleeping $6.37( \pm 1.35) \mathrm{h}$ per night, lower than the 7-8 $\mathrm{h}$ per night that is recommended [38]. Perceived level of distress was reported as $4.02( \pm 2.78)$ and CES-D depression score was $13.9( \pm 9.17)$ with $36.1 \%$ reporting scores at or above 16 (the criteria for clinical depression).

\subsection{Health Indicators by Income and Job Position}

Significant differences were noted between participants making below $\$ 20,000$ compared to those with an income above $\$ 20,000$. Specifically, lower income participants were significantly more likely to be current smokers (19.9\% vs. $11.7 \%, p=0.0057)$, drink more sugar-sweetened beverages on a daily basis (1.9 vs. $1.5, p=0.0057)$, and report higher depressive symptoms (15.5 vs. $12.6, p=0.0002)$. A higher percentage of lower income participants were classified as at or above the typical cutoff of $16(41.6 \%$ vs. $31.3 \%, p=0.0094)$. The lowest income participants (below $\$ 20,000)$ were also less sedentary (468 $\mathrm{min} /$ day vs. $491 \mathrm{~min} /$ day, $p=0.0006$ ). There were few differences in health indicators by job position; however, compared with staff, administrators accumulated an average of $26 \mathrm{~min}$ less of MVPA per week (126 vs. $100 \mathrm{~min} /$ week, $p=0.0048$ ) and 24 more minutes of sedentary time per day (477 vs. $501 \mathrm{~min} /$ day, $p=0.0051$ ).

\subsection{Indicators of Working Conditions Overall}

Job-related health risk indicators are reported in Table 4. On average, participants reported that they worked $41.6( \pm 11.8) \mathrm{h}$ per week. On average, they rated their job demand as $12.6( \pm 2.2)$ and job control as $24.3( \pm 5.18)$.

\subsection{Indicators of Working Conditions by Income and Job Position}

There were statistically significant differences in working conditions by income and job position. Not surprisingly, participants making less than $\$ 20,000$ worked fewer hours compared to those making above $\$ 20,000$ (39.8 vs. $43.5 \mathrm{~h}, p=0.0001$ ). The lowest income participants had less job control, on average (reverse coding, 25.1 vs. 23.4, $p=0.0001$ ) and lower job demands (12.4 vs. 12.8, $p=0.0355$ ). Administrators worked more hours compared to staff ( 46.4 vs. $40.6 \mathrm{~h}, p=0.0001$ ) and were less likely to report perceived job insecurity $(6.03 \%$ vs. $12.5 \%, p=0.0468)$. Administrators reported higher job demands (13.3 vs. $12.5, p=0.0007)$ and better job control (21.6 vs. $24.9, p=0.0001)$.

\section{Discussion}

This study describes health indicators on a sample of child care workers and selected contextual factors that provide insight into their work environment. Our results align with national data that child care workers are truly low wage workers. Our data also suggest that these workers exhibit many health risks such as excess weight, insufficient activity, unhealthy diet, inadequate sleep, and depressive symptoms. In addition to the hardship posed by low wages, our results confirm challenges of their working conditions such as long hours and high job demands and low job control. Also, this is the first study to explore differences in health and working conditions by household income $( \pm \$ 20,000)$ and job position (administrators vs. staff). Below, we emphasize the importance of these results in relation to existing literature, with a goal of improving future research and practice with child care workers.

The results of this study offer a valuable contribution to research into the health of child care workers, a population that has been largely ignored. Obesity (not just overweight) was an issue for the majority of child care workers in this study. Estimates from our study as well as the study by Sharma and colleagues of Head Start teachers, indicate a higher obesity prevalence among child care workers compared to the general U.S. population of adult women ( $66.3 \%$ and $54.5 \%$ vs. $40.4 \%$, respectively) [12,39]. Obesity, in turn, increases risk for a wide array of chronic diseases, including cancer, heart disease, diabetes, kidney disease, and arthritis [40-42]. Interestingly, a greater portion of child care workers in this study appear to be sufficiently active compared to the general US population ( $27.8 \%$ vs. $10.7 \%$, when applying the same cut points) [43]. These child care workers reported dietary intake and sleep patterns that are similar to the general population, but again behaviors fall 
short of national recommendations for overall health. For example, child care workers in our study reported eating fruits and vegetables an average of 2.6 times per day, which is similar to the average of 2.7 servings consumed by adults nationwide [44]; however, both groups fall short of the 3.5-4.5 cups recommended for women [37]. Similarly, child care workers in this study reported $6.4 \mathrm{~h}$ of sleep per night, which is slightly less than $6.9 \mathrm{~h}$ of sleep per night that most US adults report; however, both are slightly below national recommendations of 7-8 $\mathrm{h}$ per night [38].

An alarming $36.1 \%$ of participants in this study reported CES-D depression scores at or above the criteria for clinical depression, which far exceeds the national rate of depression for Americans (7.6\%) and the rate among women between 40-59 years old (12.3\%) [45]. This finding corroborates previous research demonstrating elevated levels of depressive symptoms among child care workers, including one study that found depressive symptoms among a nearly a quarter $(24 \%)$ of child care staff in Head Start programs in Pennsylvania $[46,47]$. Depression and obesity often co-occur, so that our results warrant further investigation into the reasons why child care workers have high rates of both conditions, and, to explore effective ways of reducing their incidence and unhealthy impacts.

Our results also indicate that the lowest paid childcare workers are more likely to report multiple unhealthy behaviors. For example, they are more likely to be current smokers, drink more sweetened beverages, and report higher depressive symptoms. One potential explanation for this pattern of unhealthy behaviors is that lower wage workers are using food, beverages, or cigarettes as a way to cope with challenging work and/or financial conditions. While we cannot be certain of this explanation, we know that these behavioral choices contribute to poor health [48-50], and there is evidence from the literature to suggest that lower income populations are more likely to engage in these behaviors [51-53]. Future examinations of child care worker health behaviors would benefit from qualitative research that examines how and why these individuals are more likely to smoke or drink sweetened beverages. Then, the next generation of interventions could be tailored to the expressed needs of these individuals. For example, stress management may be a critical component of dietary and/or smoking interventions. And, interventions may need to address the underlying issues related to financial strain, either by offering assistance with finance management strategies and/or advocating for living wages.

In addition to the numerous health issues faced by child care workers, our study also highlights their challenging working conditions, including differences by job position. Consistent with existing literature, our study should serve as a call to action for addressing the child care work environment and its impact on workers' stress and well-being [13]. Our results indicate that administrators report higher demands and higher job control than staff. We may want to investigate ways to increase the job control of the lowest income childcare workers, which are typically staff. A qualitative study by Faulkner and colleagues with home-based and center-based child care workers found that common stressors were parental interactions, caregiving, and the failure of public perception to see child care as a profession [54]. Child care workers also reported sleep disruptions (e.g., dreaming about children/work), and physical exhaustion. Child care work can be challenging, especially for administrators, who are the key gatekeepers to the child care setting. Although new interventions could be helpful, researchers should consider the readiness and capacity of child care administrators and staff when developing interventions so as not to add unnecessary burden to workers as part of well-intentioned initiatives.

Our study offers many lessons to help inform future child care-based interventions. Findings emphasize the importance of child care as a setting through which to target health initiatives, especially for those wanting to intervene with low-income women. Like other low wage earners, child care workers experience many risks to their health and well-being. These risks sometimes affect child care workers differently, based on their income and job position. Thus, future efforts to improve the health of child care workers will benefit from multi-level interventions that not only promote healthy behaviors, but also address underlying and interconnected issues related to living wages, health care benefits, and working conditions. Child care workers would also benefit from a coordinated approach to health that not only addresses physical inactivity and dietary behaviors, but also stress 
management and healthy coping skills. Additionally, it is not enough to focus only on the child care worker, we must address the directors, supervisors, and conditions under which these individuals operate, e.g., the entire work environment. Since child care centers are considered small businesses, we know that these organizations are less likely to provide worksite wellness and health promotion programs, policies, and environmental supports than larger employers [55-57]. With more than one million child care workers nationwide, many of whom are women, we need to build the evidence base for effective interventions that are tailored to this important segment of the workforce.

We acknowledge several strengths and limitations of this study. A major strength of this study is its contribution to what is currently a very limited body of literature on the health of child care workers. Our study is unique in that it includes data on the child care worker, her health status and health behaviors, and her working conditions. Another strength is the use of objective measures of several physical health indicators (e.g., physical activity, weight, waist circumference, blood pressure). Study limitations are related to cross-sectional data, possible self-selection bias, self-report bias, and unmeasured factors that may impact our findings. Specifically, because our data are cross-sectional at baseline, we cannot establish temporality of our results. We expect to be able to explore changes over time in the larger study which will have multiple measures over time. Another limitation is that we cannot generalize our findings beyond the sample of child care workers in North Carolina due to potential selection bias both at the center and participant levels. Although we cannot be certain of the impact of the bias, it is plausible that volunteers willing to participate in the worksite wellness intervention trial may be healthier than who do not participate. However, upon comparing characteristics of our final sample to the workforce in North Carolina using data from the 2015 Child Care Workforce Survey [58] we found that they appear to be similar in terms of income, education, and quality rating. While we used mostly self-report data which introduces another source of bias, we used primarily well-established instruments with sound psychometric evidence whenever available. In addition, our results may be influenced by unmeasured factors. For example, we did not measure years of work experience, but we know that in North Carolina, directors are in their positions, on average, for 6.4 years, teachers for 3.6 years, and teachers assistants for 2.5 years [58]. So the results we report based on income and/or job position may be better understood if we knew length of time in child care. It is also likely that the relationships we discovered are due to an overlap between income and job position. We did not collect data on the relationship between administrators and staff which can contribute to high job strain if these relationships are negative or otherwise unsupportive. And, we have no information about the stress that child care workers may be under at home which will also likely influence health $[59,60]$. These are several examples of unmeasured variables that could provide additional insights about our results and future studies should consider.

The next generation of research might benefit from considering integrated interventions that address both health promotion and occupational health and safety. The National Institute of Occupational Safety and Health (NIOSH) is advocating for "Total Worker Health" interventions that may be particularly appropriate for this group of workers and workplaces [61,62]. Moreover, future research should include mixed methods studies that would explore reasons why child care workers practice unhealthy behaviors or rate work experiences as high demand/low control; as well as work with center administrators to determine who can best influence the policies and practices in place at child care centers. Promoting the health of child care workers at the workplace with health programs, policies, and environmental supports, along with higher wages, is critical.

\section{Conclusions}

Child care centers are located in all states and employ over 1.3 million workers nationally [4]. While our results are specific to those who participated in this study, these findings provide useful insights for the larger population of child care workers nationally. These results represent an important call to action for researchers, policy makers, and community leaders who can advocate for living 
wages for these important members of the workforce, and plan interventions to improve the health and well-being of child care workers in the context of their everyday work conditions.

Acknowledgments: We would like to acknowledge the study interventionist, Ellie Morris, as well as the research assistants, data collectors, and all participating child care staff in this study. This research was funded by the National Heart, Lung, And Blood Institute of the National Institutes of Health (NIH) under award number R01HL119568. This project was conducted out of the Center for Health Promotion and Disease Prevention, a Prevention Research Center funded through a cooperative agreement with the Center for Disease Control and Prevention (CDC) under award number U48DP001944. The content is solely the responsibility of the authors and does not necessarily represent the official views of the NIH or the CDC.

Author Contributions: Laura Linnan, Dianne Ward, Amber Vaughn, and Lori A. Bateman conceived and designed the study. Lori A. Bateman and Natalie Smith led data collection and processing. Natalie Smith undertook statistical/data analysis. Laura Linnan, Dianne Ward, and Natalie Smith led interpretation of data. Laura Linnan, Gabriela Arandia, Lori A. Bateman, Amber Vaughn, Natalie Smith, and Dianne Ward drafted the manuscript. Laura Linnan, Dianne Ward, and Amber Vaughn obtained funding to carry out the study. All authors were involved in preparing the outline of the manuscript, making comments on the manuscript, and approved the final version of the article.

Conflicts of Interest: The authors declare no conflict of interest.

\section{References}

1. Occupational Outlook Handbook, 2016-2017 Edition, Childcare Workers. Available online: http://www.bls. gov/ooh/personal-care-and-service/childcare-workers.htm (accessed on 10 February 2016).

2. Bureau of Labor Statistics. Women in the Labor Force: A Databook; Bureau of Labor Statistics: Washington, DC, USA, 2015; pp. 1-105.

3. National Survey of Early Care. Number and Characteristics of Early Care and Education (ECE) Teachers and Caregivers: Initial Findings from the National Survey of Early Care and Education (NSECE); OPRE Report \#2013-38; U.S. Department of Health and Human Services: Washington, DC, USA, 2013.

4. Whitebook, M.; McLean, C.; Austin, L.J.E. Early Childhood Workforce Index-2016; Center for the Study of Child Care Employment, University of California: Berkeley, CA, USA, 2016.

5. Kanervisto, M.V.T.; Laitinen, T.; Heliovaara, M.; Jousilahti, P.; Saarelainen, S. Low socioeconomic status is associated with chronic obstructive airway diseases. Respir. Med. 2011, 105, 1140-1146. [CrossRef] [PubMed]

6. Kanjilal, S.G.E.; Cheng, Y.J.; Zhang, P.; Nelson, D.E.; Mensah, G.; Beckles, G.L. Socioeconomic status and trends in disparities in 4 major risk factors for cardiovascular disease among U.S. adults, 1971-2002. Arch. Intern. Med. 2006, 166, 2348-2355. [CrossRef] [PubMed]

7. Singh, G.K. Widening socioeconomic inequalities in U.S. life expectancy, 1980-2000. Int. J. Epidemiol. 2006, 35, 969-979. [CrossRef] [PubMed]

8. Landsbergis, P.A.; Grzywacz, J.G.; LaMontagne, A.D. Work organization, job insecurity, and occupational health disparities. Am. J. Ind. Med. 2014, 57, 495-515. [CrossRef] [PubMed]

9. Whitaker, R.C.; Becker, B.D.; Herman, A.N.; Gooze, R.A. The physical and mental health of head start staff: The Pennsylvania head start staff wellness survey, 2012. Prev. Chronic Dis. 2013, 10, E181. [CrossRef] [PubMed]

10. Baldwin, D.; Gaines, S.; Wold, J.L.; Williams, A.; Leary, J. The health of female child care providers: Implications for quality of care. J. Community Health Nurs. 2007, 24, 1-17. [CrossRef] [PubMed]

11. Tovar, A.; Vaughn, A.; Grummon, A.; Burney, R.; Erinosho, T.; Østbye, T.; Ward, D. Family child care home providers as role models for children: Cause for concern? Prev. Med. Rep. 2016. [CrossRef] [PubMed]

12. Sharma, S.; Dortch, K.S.; Byrd-Williams, C.; Truxillio, J.B.; Rahman, G.A.; Bonsu, P.; Hoelscher, D. Nutrition-related knowledge, attitudes, and dietary behaviors among head start teachers in Texas: A cross-sectional study. J. Acad. Nutr. Diet. 2013, 113, 558-562. [CrossRef] [PubMed]

13. Cumming, T. Early childhood educators' well-being: An updated review of the literature. Early Child. Educ. J. 2016. [CrossRef]

14. Bright, K.A.; Calabro, K. Child care workers and workplace hazards in the United States: Overview of research and implications for occupational health professionals. Occup. Med. 1999, 49, 427-437. [CrossRef]

15. Gratz, R.R.; Claffey, A.; King, P.; Scheuer, G. The physical demands and ergonomics of working with young children. Early Child Dev. Care 2002, 172, 531-537. [CrossRef] 
16. King, P.M.; Gratz, R.; Kleiner, K. Ergonomic recommendations and their impact on child care workers' health. Work 2006, 26, 13-17. [PubMed]

17. North Carolina Division of Child Development and Early Education. Available online: http://ncchildcaresearch.dhhs.state.nc.us/ (accessed on 12 August 2016).

18. Warburton, D.E.R.; Jamnik, V.K.; Bredin, S.S.D.; Gledhill, N. International launch of the PAR-Q+ and EPARMED-X+ the physical activity readiness questionnaire (PAR-Q+) and electronic physical activity readiness medical examination (EPARMED-X+). Health Fit. J. Can. 2011, 4, 3-17.

19. National Health and Nutrition Examination Survey (NHANES): Anthropometry Procedures Manual. Available online: https://www.cdc.gov/nchs/data/nhanes/nhanes_07_08/manual_an.pdf (accessed on 1 December 2016).

20. Pickering, T.G.; Hall, J.E.; Appel, L.J.; Falkner, B.E.; Graves, J.; Hill, M.N.; Jones, D.W.; Kurtz, T.; Sheps, S.G.; Roccella, E.J. Recommendations for blood pressure measurement in humans and experimental animals: Part 1: Blood pressure measurement in humans: A statement for professionals from the subcommittee of professional and public education of the American heart association council on high blood pressure research. Hypertension 2005, 45, 142-161. [PubMed]

21. Matthews, C.E.; Chen, K.Y.; Freedson, P.S.; Buchowski, M.S.; Beech, B.M.; Pate, R.R.; Troiano, R.P. Amount of time spent in sedentary behaviors in the United States, 2003-2004. Am. J. Epidemiol. 2008, 167, 875-881. [CrossRef] [PubMed]

22. Troiano, R.P.; Berrigan, D.; Dodd, K.W.; Masse, L.C.; Tilert, T.; McDowell, M. Physical activity in the United States measured by accelerometer. Med. Sci. Sports Exerc. 2008, 40, 181-188. [CrossRef] [PubMed]

23. UNC Chai Core Carolina Health Assessment and Research Tool (CHART). Available online: http://chaicore. com/home (accessed on 29 May 2016).

24. Thompson, F.E.; Midthune, D.; Subar, A.F.; McNeel, T.; Berrigan, D.; Kipnis, V. Dietary intake estimates in the national health interview survey, 2000: Methodology, results, and interpretation. J. Am. Diet. Assoc. 2005, 105, 352-363. [CrossRef] [PubMed]

25. Thompson, F.E.; Midthune, D.; Subar, A.F.; Kahle, L.L.; Schatzkin, A.; Kipnis, V. Performance of a short tool to assess dietary intakes of fruits and vegetables, percentage energy from fat and fibre. Public Health Nutr. 2004, 7, 1097-1105. [CrossRef] [PubMed]

26. Block, G.; Woods, M.; Potosky, A.; Clifford, C. Validation of a self-administered diet history questionnaire using multiple diet records. J. Clin. Epidemiol. 1990, 43, 1327-1335. [CrossRef]

27. Centers for Disease Control and Prevention. Behavioral Risk Factor Surveillance System (BRFSS). Available online: http:/ / www.cdc.gov/brfss/ (accessed on 29 May 2016).

28. Buysse, D.J.; Reynolds, C.F., 3rd; Monk, T.H.; Berman, S.R.; Kupfer, D.J. The Pittsburgh sleep quality index: A new instrument for psychiatric practice and research. Psychiatry Res. 1989, 28, 193-213. [CrossRef]

29. Society for Behavioral Medicine's Health Policy Committee. The public health need for patient-reported measures and health behaviors in electronic health records: A policy statement of the society of behavioral medicine. Transl. Behav. Med. 2011, 1, 108-109.

30. Radloff, L.S. The CES-D scale: A self-report depression scale for research in the general population. Appl. Psychol. Meas. 1977, 1, 385-401. [CrossRef]

31. Karasek, R.; Brisson, C.; Kawakami, N.; Houtman, I.; Bongers, P.; Amick, B. The job content questionnaire (JCQ): An instrument for internationally comparative assessments of psychosocial job characteristics. J. Occup. Health Psychol. 1998, 3, 322-355. [CrossRef] [PubMed]

32. Slopen, N.; Glynn, R.J.; Buring, J.E.; Lewis, T.T.; Williams, D.R.; Albert, M.A. Job strain, job insecurity, and incident cardiovascular disease in the women's health study: Results from a 10-year prospective study. PLoS ONE 2012, 7, e40512. [CrossRef] [PubMed]

33. 2016 Federal Poverty Guidelines. Available online: https:/ / aspe.hhs.gov/poverty-guidelines (accessed on 2 December 2016).

34. North Carolina Quality Rating and Improvement System Profile. Available online: https:/ qrisguide.acf. hhs.gov/files/111109_NC_QRIS_Profile_0.pdf (accessed on 8 December 2016).

35. National Heart Lung and Blood Institute; National Institutes of Health. Classification of Overweight and Obesity by BMI, Waist Circumference, and Associated Disease Risks. Available online: https:/ /www.nhlbi. nih.gov/health/educational/lose_wt/BMI/bmi_dis.htm (accessed on 21 December 2016). 
36. U.S. Department of Health and Human Services. 2008 Physical Activity Guidelines for Americans; U.S. Department of Health and Human Services: Washington, DC, USA, 2008; p. 61.

37. United States Department of Agriculture, MyPlate. Available online: https://www.choosemyplate.gov/ MyPlate (accessed on 12 December 2016).

38. Centers for Disease Control and Prevention. Are You Getting Enough Sleep? Available online: https: / /www.cdc.gov / features/sleep/ (accessed on 12 December 2016).

39. Flegal, K.M.; Kruszon-Moran, D.; Carroll, M.D.; Fryar, C.D.; Ogden, C.L. Trends in obesity among adults in the United States, 2005 to 2014. JAMA 2016, 315, 2284-2291. [CrossRef] [PubMed]

40. Guh, D.P.; Zhang, W.; Bansback, N.; Amarsi, Z.; Birmingham, C.L.; Anis, A.H. The incidence of co-morbidities related to obesity and overweight: A systematic review and meta-analysis. BMC Public Health 2009, 9, 88. [CrossRef] [PubMed]

41. Zalesin, K.C.; Franklin, B.A.; Miller, W.M.; Peterson, E.D.; McCullough, P.A. Impact of obesity on cardiovascular disease. Endocrinol. Metab. Clin. N. Am. 2008, 37, 663-684. [CrossRef] [PubMed]

42. Flegal, K.M.; Kit, B.K.; Orpana, H.; Graubard, B.I. Association of all-cause mortality with overweight and obesity using standard body mass index categories: A systematic review and meta-analysis. JAMA 2013, 309, 71-82. [CrossRef] [PubMed]

43. Watson, K.B.; Carlson, S.A.; Carroll, D.D.; Fulton, J.E. Comparison of accelerometer cut points to estimate physical activity in U.S. adults. J. Sports Sci. 2014, 32, 660-669. [CrossRef] [PubMed]

44. Moore, L.V.; Thompson, F.E. Adults meeting fruit and vegetable intake recommendations-United States, 2013. MMWR Morb. Mortal Wkly. Rep. 2015, 64, 709-713. [PubMed]

45. Pratt, L.A.; Brody, D.J. Depression in the U.S. Household Population, 2009-2012; Centers for Disease Control: Hyattsville, MD, USA, 2014.

46. Whitaker, R.C.; Dearth-Wesley, T.; Gooze, R.A. Workplace stress and the quality of teacher-children relationships in head start. Early Child. Res. Quart. 2015, 30, 57-69. [CrossRef]

47. Hamre, B.K.; Pianta, R.C. Self-reported depression in nonfamilial caregivers: Prevalence and associations with caregiver behavior in child-care settings. Early Child. Res. Quart. 2004, 19, 297-318. [CrossRef]

48. Kulie, T.; Slattengren, A.; Redmer, J.; Counts, H.; Eglash, A.; Schrager, S. Obesity and women's health: An evidence-based review. J. Am. Board Fam. Med. 2011, 24, 75-85. [CrossRef] [PubMed]

49. Imamura, F.; O'Connor, L.; Ye, Z.; Mursu, J.; Hayashino, Y.; Bhupathiraju, S.N.; Forouhi, N.G. Consumption of sugar sweetened beverages, artificially sweetened beverages, and fruit juice and incidence of type 2 diabetes: Systematic review, meta-analysis, and estimation of population attributable fraction. Br. J. Sports Med. 2016, 50, 496-504. [CrossRef] [PubMed]

50. U.S. Department of Health and Human Services. The Health Consequences of Smoking - 50 Years of Progress: A Report of the Surgeon General; U.S. Department of Health and Human Services: Atlanta, GA, USA, 2014.

51. Hiscock, R.; Bauld, L.; Amos, A.; Fidler, J.A.; Munafò, M. Socioeconomic status and smoking: A review. Ann. N. Y. Acad. Sci. 2012, 1248, 107-123. [CrossRef] [PubMed]

52. Han, E.; Powell, L.M. Consumption patterns of sugar-sweetened beverages in the United States. J. Acad. Nutr. Diet. 2013, 113, 43-53. [CrossRef] [PubMed]

53. Hiza, H.A.; Casavale, K.O.; Guenther, P.M.; Davis, C.A. Diet quality of Americans differs by age, sex, race/ethnicity, income, and education level. J. Acad. Nutr. Diet. 2013, 113, 297-306. [CrossRef] [PubMed]

54. Faulkner, M.; Gerstenblatt, P.; Lee, A.; Vallejo, V.; Travis, D. Childcare providers: Work stress and personal well-being. J. Early Child. Res. 2014, 14, 280-293. [CrossRef]

55. McLellan, D.L.; Caban-Martinez, A.J.; Nelson, C.C.; Pronk, N.P.; Katz, J.N.; Allen, J.D.; Davis, K.L.; Wagner, G.R.; Sorensen, G. Organizational characteristics influence implementation of worksite health protection and promotion programs: Evidence from smaller businesses. J. Occup. Environ. Med. 2015, 57, 1009-1016. [CrossRef] [PubMed]

56. Harris, J.R.; Hannon, P.A.; Beresford, S.A.; Linnan, L.A.; McLellan, D.L. Health promotion in smaller workplaces in the United States. Annu. Rev. Public Health 2014, 35, 327-342. [CrossRef] [PubMed]

57. Baron, S.L.; Beard, S.; Davis, L.; Delp, L.; Forst, L.; Kidd-Taylor, A.; Liebman, A.K.; Linnan, L.; Punnet, L.; Welch, L. Promoting an integrated approach to reducing health inequities among low-income workers: Applying a social ecological framework. Am. J. Ind. Med. 2013, 57, 539-556. [CrossRef] [PubMed]

58. North Carolina Child Care Workforce Study. Available online: http://www.childcareservices.org/wpcontent/uploads/2016/01/2015-Workforce-Report-FNL.pdf (accessed on 5 December 2016). 
59. McMillan, H.S.; Morris, M.L.; Atchley, E.K. Constructs of the work/life interface: A synthesis of the literature and introduction of the concept of work/life harmony. Hum. Resour. Dev. Rev. 2011, 10, 6-25. [CrossRef]

60. Ertel, K.A.; Koenen, K.C.; Berkman, L.F. Incorporating home demands into models of job strain: Findings from the work, family \& health network. J. Occup. Environ. Med./Am. Coll. Occup. Environ. Med. 2008, $50,1244$.

61. Sorensen, G.; McLellan, D.L.; Sabbath, E.L.; Dennerlein, J.T.; Nagler, E.M.; Hurtado, D.A.; Pronk, N.P.; Wagner, G.R. Integrating worksite health protection and health promotion: A conceptual model for intervention and research. Prev. Med. 2016, 91, 188-196. [CrossRef] [PubMed]

62. Punnett, L.; Cherniack, M.; Henning, R.; Morse, T.; Faghri, P.; Team, C.-N.R. A conceptual framework for integrating workplace health promotion and occupational ergonomics programs. Public Health Rep. 2009, 124, 16-25. [CrossRef] [PubMed]

(C) 2017 by the authors. Licensee MDPI, Basel, Switzerland. This article is an open access article distributed under the terms and conditions of the Creative Commons Attribution (CC BY) license (http:/ / creativecommons.org/licenses/by/4.0/). 